\title{
Jab1 (COPS5) as an Emerging Prognostic, Diagnostic and Therapeutic Biomarker for Human Cancer
}

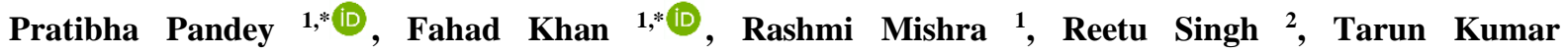 \\ Upadhyay $^{2}$ (i), Sujeet Kumar Singh 1 (i) \\ 1 Department of Biotechnology, Noida Institute of Engineering and Technology, Greater Noida \\ 2 Department of Pharmacy, Lloyd School of pharmacy, Greater Noida \\ 3 Department of Biotechnology, Parul Institute of Applied Sciences and Centre of Research for Development, Parul \\ University, Vadodara, 391760, India \\ * Correspondence: fahadintegralian@gmail.com (F.K.); shuklapratibha1985@gmail.com (P.P.); \\ Scopus Author ID 54985258500 (P.P.); 57201049984 (F.K.)
}

Received: 16.09.2021; Revised: 20.10.2021; Accepted: 24.10.2021; Published: 21.11.2021

Abstract: Jab1 (C-Jun activation domain-binding protein-1) has been reported to be critically involved in regulating apoptosis, cell proliferation, cell cycle, thereby affecting numerous pathways, DDR (DNA damage response) regulation, and genomic instability. Jab1 (CSN5) dysregulation has been positively associated with oncogenesis via activating oncogenes and deactivating various tumor suppressors. Jab1 overexpression has been reported in several tumor forms, illuminating its potent efficacy in cancer progression and metastasis. Jab1 has instigated prompt research interest in elucidating inhibitors of numerous oncoproteins and oncogenes for chemotherapeutics. Our review has presented strong evidence for presenting the significance of Jab1 overexpression in numerous carcinomas and its involvement in modulating various signaling pathways for cancer cell survival. This review may project a new way for utilizing Jab1 as a strong target for developing potent inhibitory compounds targeting Jab1 that could be further utilized in chemoprevention with limited side effects. Altogether this review further confirmed the crucial involvement of Jab1 in carcinogenesis and tumorigenesis, displaying the strong potential of Jab1 as one of the potent cancer biomarkers.

Keywords: Jab1; oncogene; cancer; diagnostic biomarker; prognostic biomarker; CSN complex.

(C) 2021 by the authors. This article is an open-access article distributed under the terms and conditions of the Creative Commons Attribution (CC BY) license (https://creativecommons.org/licenses/by/4.0/).

\begin{tabular}{l|l}
$\begin{array}{l}\text { Abbreviations } \\
\text { Jab1 }\end{array}$ & C-Jun activation domain-binding protein-1 \\
\hline COP9 signalosome & Constitutive photomorphogenic-9 \\
\hline DDR & DNA damage response \\
\hline CDK & Cyclin-dependent kinase \\
\hline PD-L1 & Programmed death-ligand 1 \\
\hline CRLs & Cullin-RING family of ubiquitin ligases \\
\hline IPA & Ingenuity pathway analysis \\
\hline APC & Adenomatous polyposis coli \\
\hline AP-1 & Activator protein 1 \\
\hline NPC & Nasopharyngeal carcinoma \\
\hline HER-2 & Human epidermal growth factor receptor-2 \\
\hline EGFR & Epidermal growth factor receptor \\
\hline USP15 & CSN associated ubiquitin specific peptidase 15
\end{tabular}

\section{Introduction}

Jab1 was formerly recognized as a c-Jun coactivator (c-Jun activation domain-binding protein-1) and consequently discovered as the 5th component of COP9 signalosome (constitutive photomorphogenic-9) [1]. Jab1 (multifunctional protein) has been associated with 
controlling a wide range of developmental and cellular processes, such as cell cycle, signal transduction, apoptosis, cells proliferation, DDR (DNA damage response), and tumorigenesis [2]. Jab1 gene, located at chromosome 8 (Q13.2), encodes Jab1 protein having $38 \mathrm{kDa}$ molecular mass [3]. Jab1 contains two domains, including JBD and MPN domain having JAMM $\left(\mathrm{Zn}^{2+}\right.$ metalloprotease) motif that represents the catalytic center of the CSN complex for isopeptidase activity, NES (nuclear export signal) domain, and PBD (p27 binding domain) [4]. Escalating evidence strongly indicates that JAB1 dysregulation is functionally associated with numerous cancer-related genes, including CDK (cyclin-dependent kinase) inhibitor, p27, p53 (transformation-related phosphoprotein), SMAD4/7, transcriptional coregulatory protein NcoR (nuclear receptor co-repressor, p57 (Cyclin-dependent kinase inhibitor), transmembrane protein PD-L1 (Programmed death-ligand 1) and so on, responsible for tumorigenesis [5]. Jab1 (oncogene) has been reported to be aberrantly overexpressed in several human carcinomas [6]. However, the mechanism behind the crucial involvement of Jab1 in cancer progression remains uncovered. Therefore, we have targeted this review to gain deeper insight into the oncogenic role of Jab1 in carcinogenesis (tumorogenesis) and its therapeutic associations with chemoprevention. Phytocompounds exhibited numerous benefits such as minimal cost, limited toxicity, and easy availability that further supported their chemopreventive potential against several carcinoma types [7]. Several classes of plant-derived compounds (such as flavonoids) have gained wider recognition via inducing significant apoptosis against several cancer cell lines, including prostate cancer (LNCaP), breast cancer (MDA-MB-231) colon cancer (HT-29) $[8,9]$.

\section{Role of Jab1 (COPS5) Binding Protein}

Jab1 (key subunit of CSN complex) play important role in integrating various functions of CSN complex [10]. CSN was originally discovered as a retardant of plant photomorphogenesis, containing eight subunits (CSN1 to CSN8) [11]. Amongst them, six subunits comprise of PCI domain that helps in CSN structure assembly, while the other two subunits consist of MPN domain [12]. Jab1 comprises of NES domain and PBD domain at Cterminal end. Jab1 transports (dislocate) p27 protein from cell nucleus in XPO1 (Exportin 1) dependent manner via NES sequence (located between amino acids 233 and 242) found at the C-terminal end of Jab1. MPN domain of Jab1 is required for regulation of cullin deneddylation process via activating CRLs (Cullin-RING family of ubiquitin ligases) [13]. Some studies have also displayed evidence supporting the isopeptidase activity of Jab1 for the progression and transformation of mammary epithelial in mice and humans [14]. Jab1 can incorporate numerous roles of CSN complex and harbors catalytic center of Jab1 isopeptidase activity of CSN. Jab1 also exists independent of the CSN complex and has been energetically involved in significant biological activities in its independent and dependent forms. Jab1 in its free form has been explored more, mainly located in both the nucleus and cytoplasm [15]. CSN modulation of CRL family of ubiquitin E3 complexes has been mainly dependent on its deneddylation role, which is executed via removal of NEDD8/Rub1 (ubiquitin-like molecules) from cullin subunit of E3 ligases. JAMM motif of Jab1 is found to be crucial to CSN deneddylation activity and is highly needed for coactivation of Jab1. CSN (multisubunit complex) controls protein stability via modulating the CRL family of ubiquitin E3 complexes, thereby acting as a key regulator of various cellular processes, including gene transcription, DDR, and cell cycle [16]. Jab1 in its free form has no metalloproteinase activity; thus, other 
components of CSN complex are needed for deneddylation process. Although Jab1 is located in both nuclear and cytoplasm, whether Jab1 acts either independently or in its bounded form with CSN complex in carcinogenesis needs further elucidation.

\section{Jab1 Associated Signaling Pathways in Cancer Progression}

Jab1 lies at the intersection of numerous signaling pathways, which have been reported to play vital roles in carcinogenesis [17]. Elucidating aberrant involvement of Jab1 (CSN5) in these signaling pathways might help us understand tumorigenesis. IPA (ingenuity pathway analysis) also presented a strong base for understanding the Jab1 related network and targets in several carcinomas [18]. Three key regulatory mechanisms might contribute to deregulated Jab1 expression in cancer. First, Jab1 overexpression may emerge from gene amplification. Jab1 locus has been reported to be frequently amplified in several human carcinomas (Figure $1)$.

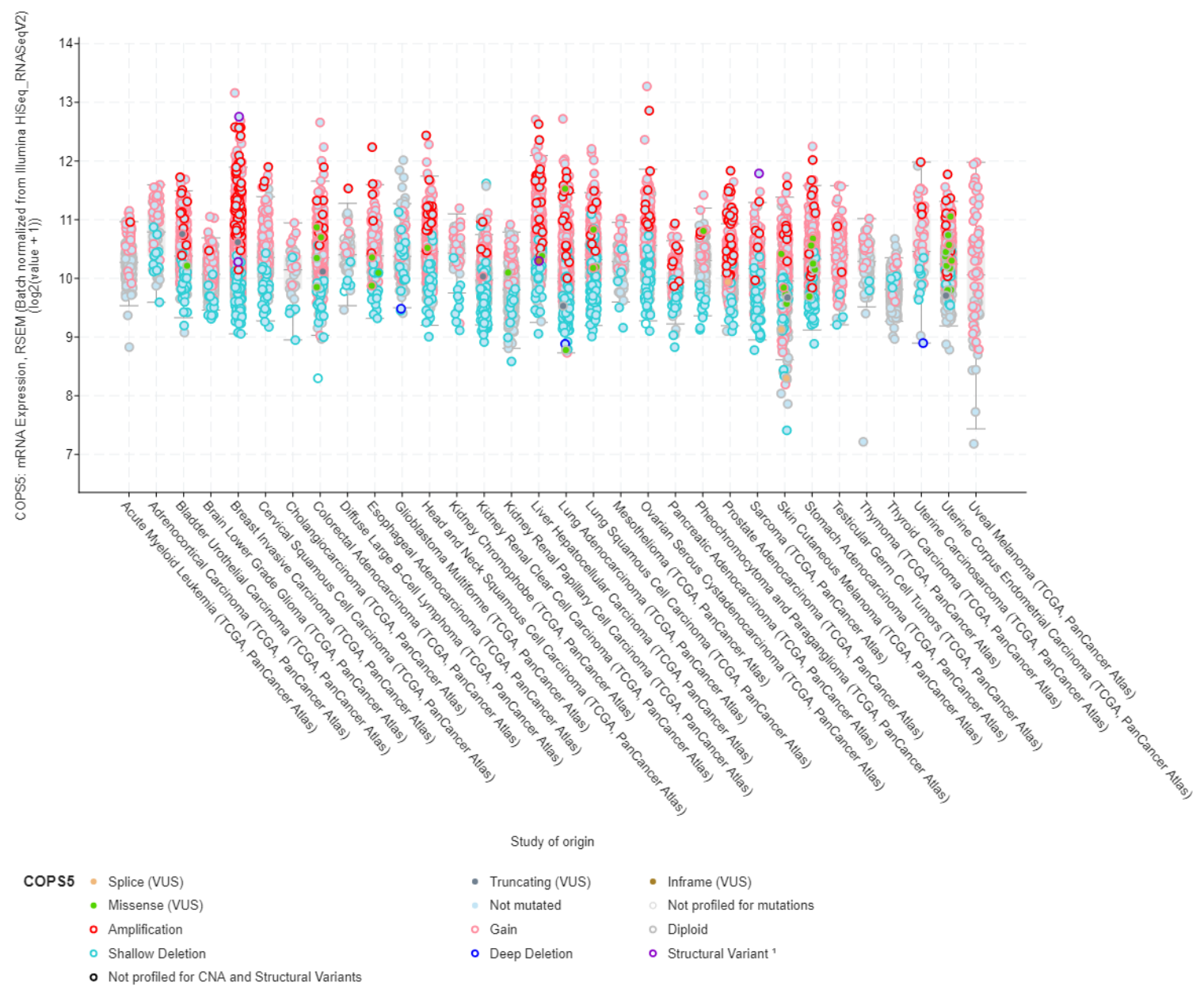

Figure 1. Amplified Jab1 overexpression in several human carcinomas.

We have presented statistics explaining DNA alteration frequency of Jab1 in several cancer types on cBioportal database (Figure 2).

Downloaded data (from cBioportal) reveals genetic alterations of Jab1 in numerous carcinomas. Second, miRNAs also modulate Jab1 expression. Thirdly, other signaling pathways also contribute greatly to Jab1 overexpression, including IL6-Stat3, Bcr-Abl, and AKT signaling, and so on, that has been described below (Figure 3). 


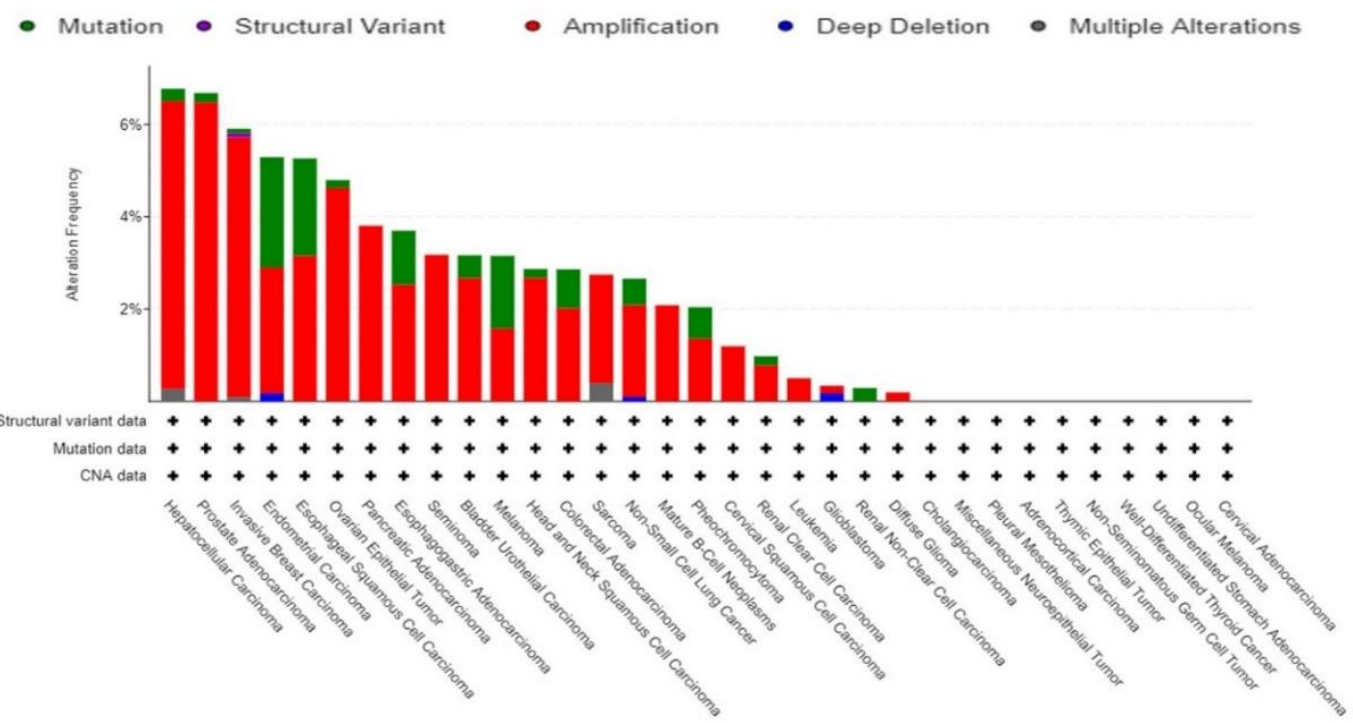

Figure 2. Statistical inference depicting DNA alteration frequency of Jab1 in various cancer types on c Bioportal database.

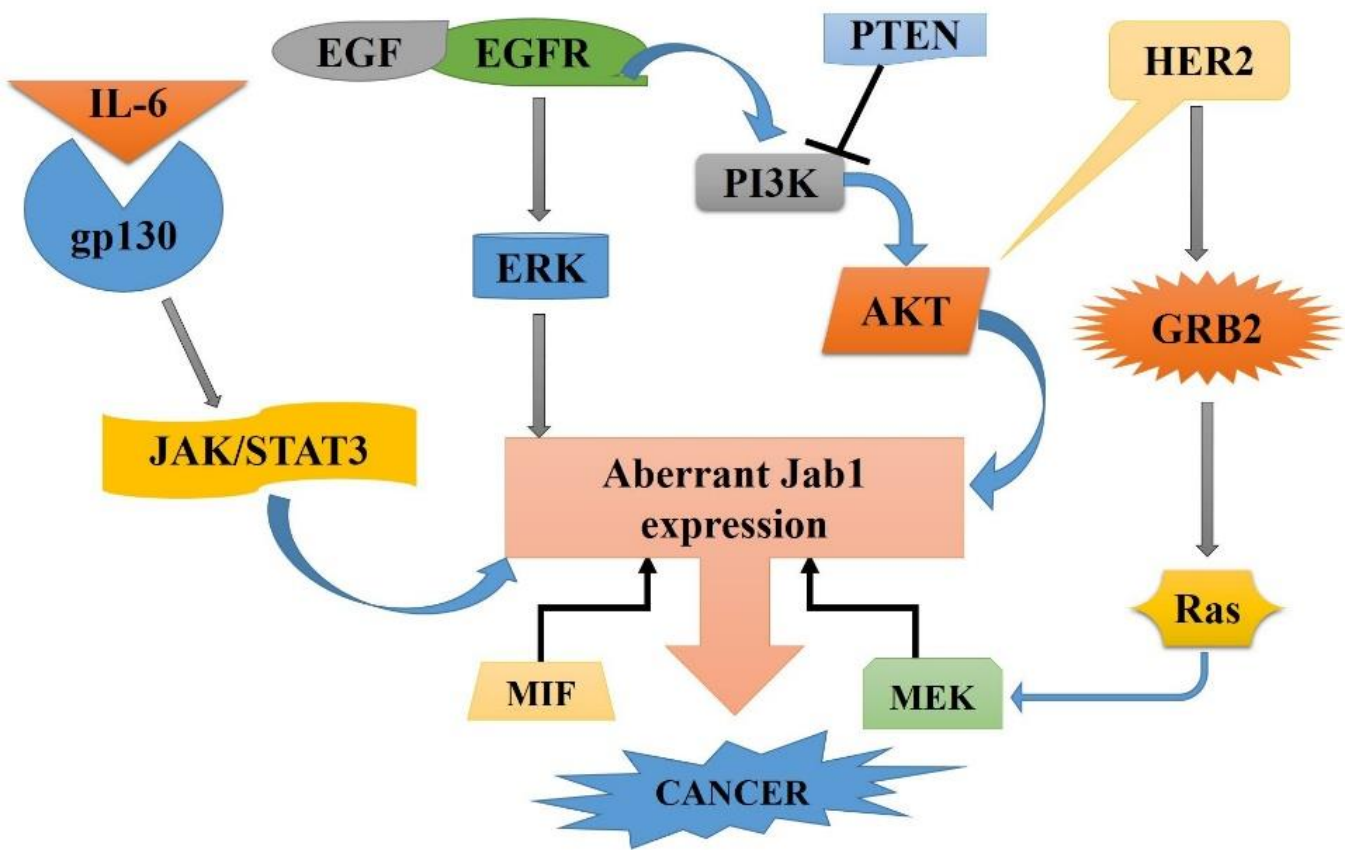

Figure 3. Schematic diagram of Jab1 cross-talk with important signaling pathways involved in cancer progression and development. HER2/Ras, EGFR/ERK, IL-6/JNK-STAT3, and PI3 K/AKT regulate Jab1 expression in numerous carcinomas.

\subsection{Jab1 in MiR-24 and IL6-Stat3 signaling.}

miR-24 has been recognized as a radiosensitizer and tumor suppressor in xenografts and NPC cells via targeting both untranslated regions (3'UTR and 5'UTR) of Jab1, leading to tumor growth inhibition and sensitization of NPC (nasopharyngeal carcinoma) cells to radiation [19]. Jab1 regulates the binding activity of unphosphorylated Stat3 via protein-protein interaction. Jab1 knockdown potentially induced reduction of unphosphorylated Stat 3 target genes and DNA-binding activity in human colon cancer cells [20]. Further research studies have revealed that Stat 3 performs its role by binding with the Jab1 promoter, thereby promoting its transcription activities. Stat 3 knockdown significantly impairs Jab1 promoter activity and reduces Jab1 protein and mRNA expression levels [21]. 
3.2. EGFR, HER-2 and TGF- $\beta$ signaling.

Jab1 overexpression has been correlated with HER-2 (human epidermal growth factor receptor-2) levels in breast cancer [22]. HER-2 elevates Jab1 promoter activity and enhances Jab1 expression via the AKT/ $\beta$-catenin pathway [23]. Herceptin has shown significant inhibitory efficacy against HER-2 Inhibition in numerous breast cancer cell lines [24]. Additionally, Jab1 has also been recognized as a potent target in EGFR (epidermal growth factor receptor) pathway. In breast cancer, Jab1 expression level has been crucially associated with EGFR level. EGFR activation promotes Jab1 translocation from cytoplasm to nucleus and modulates p27 expression level [25]. Jab1 also affects TGF- $\beta$ signaling pathway via specifically regulating subcellular localization and degradation of two main downstream targets (Smad7 and Smad4). After binding with Smad4, R-Smads (receptor-regulated Smad protein) translocates into the nucleus and activates several target gene transcription. Smad7 inhibits TGF- $\beta$ mediated responses, thereby acting in a negative feedback loop for regulating the duration and intensity of TGF- $\beta$ signal [26]. Jab1 potentiates Smad4 degradation through proteasome pathway and TGF- $\beta$ mediated attenuation of gene transcription, thereby enhancing TGF- $\beta$ signaling effects [27].

\subsection{Wnt and $N F-\kappa B$ signaling.}

Jab1controls the $\mathrm{Wnt} / \beta$-catenin signaling via favoring $\beta$-catenin-degrading complex formation through deneddylation and consequent stabilization of APC (Adenomatous polyposis coli) by CSN associated ubiquitin-specific peptidase 15 (USP15). Deregulation of balance between APC and $\beta$-catenin can lead to cancer progression via driving tumor angiogenesis, cell transformation, and metastasis [28]. Additionally, a significant reduction in $\beta$-catenin expression levels along with its phosphorylation has also been reported in Jab1 knockdown-related cancer studies such as colorectal cancer, indicating the potential involvement of Jab1 in the regulation of $\beta$-catenin/Wnt signaling pathway [29]. Jab1 has also been recognized as one of the key regulators of the NF- $\kappa \mathrm{B}$ signaling pathway via Bcl-3 (member of Iк B family) interaction, specifically in the nucleus. Jab1 co-activates Bcl-3 stimulated NF- $\kappa \mathrm{B}$ transcription via interacting with Bcl-3, and this cross-talk between CSN signalosome and NF- $\mathrm{BB}$ pathway was further validated by the fact that Jab1 regulates NF-kB activities through USP15 (CSN-associated deubiquitinase), that resulted in $\mathrm{I} \kappa \mathrm{B} \alpha$ deubiquitination [30].

\subsection{MIF-PI3K-AKT and Bcr-Abl signaling.}

Several studies have displayed indirect mechanisms associated with Jab1 and PI3K/AKT pathway regulation [31]. It has further been found that Jab1 also inhibits MIF secretion (macrophage migration inhibitory factor) along with its autocrine (pro-survival) activities and consequently controls MIF mediated AKT/PI3K signaling activation [32]. However, MIF negatively interacts with Jab1 and inhibits AP-1 (activator protein 1) and JNK kinases (c-Jun amino-terminal kinase) activity. Bcr-Abl also regulates Jab1 via cooperative interaction with $\beta$-catenin and Stat1 in leukemia cells. Also, imatinib suppressed BcrAbl by decreasing Jab1 expression in Bcr-Abl +ve leukemia cells [33]. 


\subsection{Jab1 in cancer cell growth and survival.}

Jab1 has been a key driving factor for regulating the cell cycle via favoring the degradation of numerous CKIs and cyclins. p27, also termed universal CKI, directly inhibited the enzymatic activity of cyclin-Cdk complexes, thereby leading to cell cycle growth arrest at G1 phase [34]. Further, accumulating evidence has also reported the inverse association between p27 and Jab1 expression in numerous human malignancies, such as gall bladder cancer, HCC, papillary thyroid carcinoma, Nasopharyngeal carcinoma, oral squamous, breast cancer, and prostate cancer [35]. Jab1 negatively modulates p27 expression via mediating proteasome pathway, thereby favoring cell cycle progression. Jab1 knockdown resulted in p27 accumulation in the nucleus, cell cycle growth arrest, and cell proliferation [36]. Jab1 also regulates the expression of various cell cycle regulators, including cyclin $\mathrm{D}, \mathrm{p} 21, \mathrm{p} 16, \mathrm{Bcl}-\mathrm{XL}$, and c-myc [37]. For instance, Jab1 depletion induced stability of cyclin E, whereas Jab1 overexpression induced cyclin E degradation. It is very much prominent that Jab1 plays a vital role in cell cycle regulation. Studies have also displayed that embryos of Jab1 null mice have over-expressed p53 protein and mRNA levels, supporting this oncoprotein as one of the crucial modulators of p53 stability. Targeted Jab1 disruption in mice has also resulted in early embryonic lethality leading to apoptosis. Furthermore, Jab1 depletion has also resulted in more cisplatin-, UV (ultraviolet), IR (ionizing radiation)-, or apoptotic induction, which has been correlated with p53 accumulation in NPC [38, 39]. Also, others have reported that Jab1 inhibition promoted apoptosis via modulating p53-related apoptosis pathways in several carcinomas such as breast cancer cells, gall bladder cancer cells, and gastric cancer cells. Altogether, Jab1 has been involved in numerous apoptosis-related pathways (Figure 4).

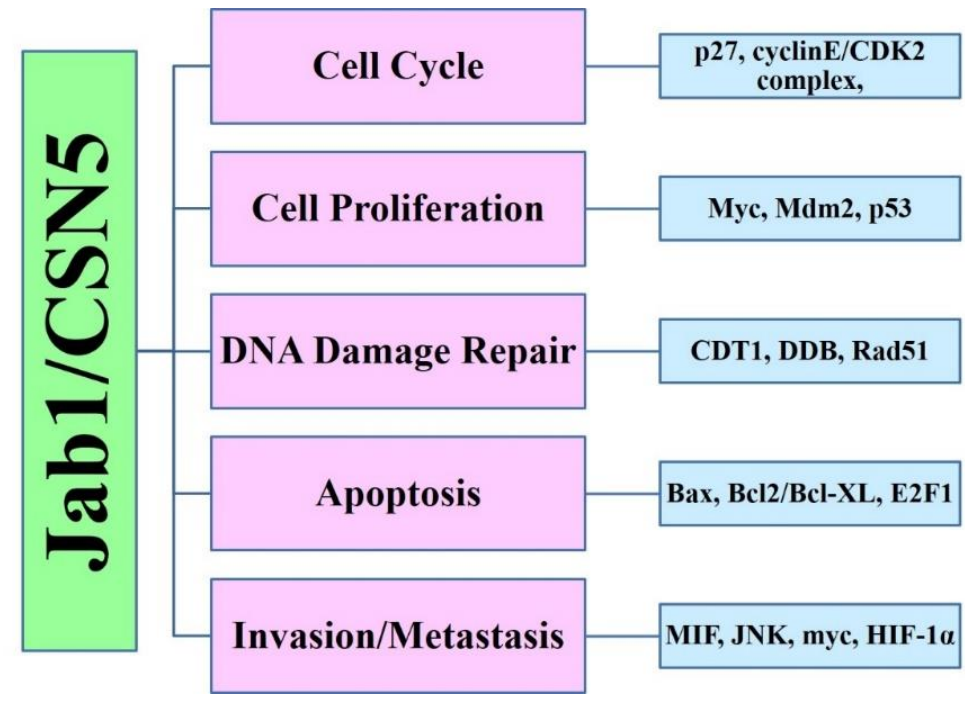

Figure 4. Jab1 involvement in apoptosis-related pathways.

\subsection{Therapeutic potential of Jab1 in carcinomas.}

Increasing evidence has strongly projected that Jab1 could be a potent therapeutic target due to its prominent involvement in various stages of carcinogenesis [40]. Since Jab1 overexpression has been generally correlated with poor prognosis, the development of Jab1 specific inhibitors would likely have a potent efficacy in cancer therapies. Numerous plantbased compounds (or chemicals) have displayed significant inhibitory potential against this crucial target responsible for cancer progression [41]. Here, we have included several phytocompounds that have shown better inhibitory efficacy against Jab1 in different cancer 
cell lines, including gall bladder cancer cells, cervical cancer cells, and prostate cancer cells. Curcumin (yellow color plant pigment) has been reported to directly inhibit the CSN associated kinases activities, thereby arresting cancer cells at the mitotic phase and making them more susceptible to apoptosis via CSN inactivation. It has also been reported that PEGylated (watersoluble) compounds inhibited the proliferation of pancreatic cancer cells by Jab1 inhibition. Further, this compound has also enhanced the sensitivity of pancreatic cancer cells for standard gemcitabine drugs. T83 (novel curcumin analog) has also potentially induced apoptosis and G2/M phase arrest in NPC cells in both time and -dose-dependent manners. Troglitazone drug has also suppressed Jab1 promoter activity via inhibiting Tcf4 and Sp1 mediated Jab1 transcription [42]. Both in vivo and in vitro researches have also strongly displayed that troglitazone drug attenuates cancer cell growth and up-regulates p27 expression level in both dose and time-dependent manner. Pandey et al. have also exploited the potential of stigmasterol for Jab1 inhibition and have strongly proven its strong Jab1 inhibitory potential in gall bladder carcinoma. Their studies further reported that stigmasterol-mediated Jab1 inhibition resulted in cell cycle, growth arrest, and apoptosis induction in gall bladder cancer cells [43]. There have been numerous studies that have presented the fact that isopeptidase activity of Jab1 resides in JAMM motif domain that can further be inhibited by $\mathrm{Zn}^{2+}$ chelators [44]. Therefore, JAMM motif of Jab1could be a strong therapeutic target since there are plenty of researches available in support of the pharmacological inhibition of metalloproteinases.

CSN5i-3 is an oral Jab1 inhibitor that blocks CRLs in a methylated state, leading to CRLs inactivation via inducing degrading their substrate recognition module $[45,46]$. These findings further supported that Jab1 inhibition has strong potencies for anti-cancer therapies. Our research study has also exploited the potential of MO (Moringa oleifera) leaf extract in modulating aberrant Jab1 expression in cervical cancer. Methanolic extract of MO leaves has also displayed potent anticancerous potential via Jab1 downregulation in cervical cancer [47]. Further, another study has also presented the inhibitory potential of hesperidin against Jab1 in cervical cancer, thereby inducing apoptosis in HeLa cancer cells. Moreover, in silico studies have also presented the strong inhibitory potential of baicalein against Jab1 [48]. Altogether, this evidence has strongly projected Jab1 as a strong therapeutic target for the management of numerous carcinomas (Table 1).

Table 1. Recent advancements in elucidating Jab1 as a potent therapeutic target in cancer management (Last 5 years).

\begin{tabular}{|c|c|c|c|}
\hline Cancer & Jab1 as a prognostic biomarker & Inhibitory mechanism & References \\
\hline Gall bladder Cancer & $\begin{array}{l}\text { Inverse correlation between Jab1 and p27 in } \\
\text { cancer progression }\end{array}$ & $\begin{array}{l}\text { Jab1siRNA induces apoptosis via enhancing p27 } \\
\text { expression in gall bladder cancer }\end{array}$ & [49] \\
\hline Breast cancer & $\begin{array}{l}\text { Jab1 as a potential therapeutic target of EGFR } \\
\text { signaling pathways in ER } \alpha \text { - breast cancer. }\end{array}$ & $\begin{array}{l}\text { ERK pathway inhibitor PD98059 has } \\
\text { downregulated Jab1 expression and up-regulated } \\
\text { p27 expression in breast tumors }\end{array}$ & {$[50]$} \\
\hline Breast cancer & $\begin{array}{l}\text { Inverse correlation between Let-7d and Jab1 } \\
\text { expression in breast cancer progression }\end{array}$ & $\begin{array}{l}\text { Let-7d Inhibits Growth and Metastasis in Breast } \\
\text { Cancer by Targeting Jab1/Cops } 5\end{array}$ & {$[51]$} \\
\hline Breast cancer & $\begin{array}{l}\text { Overexpression of MRPS30-DT and Jab1 mRNA } \\
\text { expressions in cancer progression }\end{array}$ & $\begin{array}{l}\text { MRPS30-DT siRNAs reduced Jab1 expression in } \\
\text { breast cancer cells (MDA-MB-231 and MCF-7) }\end{array}$ & {$[52]$} \\
\hline Breast cancer & $\begin{array}{l}\text { p38MAPK-MK2 signaling pathway promoted } \\
\text { triple-negative breast cancer tumorigenesis via } \\
\text { sustaining AP1 activity through Ser177 } \\
\text { phosphorylation of JAB1 }\end{array}$ & $\begin{array}{l}\text { JAB1 silencing resulted in a dramatic reduction in } \\
\text { cell growth and in vivo tumor outgrowth in Triple- } \\
\text { negative breast cancer cells }\end{array}$ & {$[53]$} \\
\hline Breast cancer & $\begin{array}{l}\text { ErbB2 downstream signaling proteins, including } \\
\text { PI3 (phosphatidylinositol 3) kinase and AKT } \\
\text { (protein kinase B), were activated by Jab1 } \\
\text { overexpression in SKBr3 breast cancer cells. }\end{array}$ & $\begin{array}{l}\text { Jab1 downregulation might provide a new avenue } \\
\text { in breast cancer management }\end{array}$ & [54] \\
\hline Cervical Cancer & $\begin{array}{l}\text { Inverse correlation between p } 27 \text { and Jab1 gene in } \\
\text { cervical cancer progression }\end{array}$ & $\begin{array}{l}\text { Methanolic Extract of MO (Moringa oleifera) } \\
\text { leaves showed a prominent reduction in Jab1 }\end{array}$ & [55] \\
\hline
\end{tabular}




\begin{tabular}{|c|c|c|c|}
\hline Cancer & Jab1 as a prognostic biomarker & Inhibitory mechanism & References \\
\hline & & $\begin{array}{l}\text { expression, thereby inhibiting cervical cancer cell } \\
\text { growth. }\end{array}$ & \\
\hline Lung Cancer & $\begin{array}{l}\alpha 5-\mathrm{nAChR} \text { expression was positively correlated } \\
\text { with Jab1 expression in lung cancer progression }\end{array}$ & $\begin{array}{l}\text { Downregulation of } \alpha 5-\mathrm{nAChR} \text { reduced Jab1 } \\
\text { expression and silencing of these crucial } \\
\text { biomarkers } \alpha 5-\mathrm{nAChR} \text { or Jab1/Csn } 5 \text { inhibited the } \\
\text { invasion and migration of lung cancer cells }\end{array}$ & [56] \\
\hline Colorectal Cancer & $\begin{array}{l}\text { Jab1 positively regulates the expression of c- } \\
\text { MYC, nuclear } \beta \text {-catenin, and cell cycle } \\
\text { regulators, including topoisomerase II } \alpha \text { and Ki- } \\
67 \text { in human Colorectal cancer cells. }\end{array}$ & $\begin{array}{l}\text { JAB } 1 \text { emerged as a promising target for potent } \\
\text { Colorectal cancer therapy }\end{array}$ & [57] \\
\hline Gastric Cancer & $\begin{array}{l}\text { The correlation between p14ARF and Jab1 might } \\
\text { provide new avenues in the treatment of gastric } \\
\text { cancer. }\end{array}$ & $\begin{array}{l}\text { Jab1 promotes gastric cancer cell growth via } \\
\text { decreasing p14ARF expression through } \\
\text { proteasomal degradation. }\end{array}$ & [58] \\
\hline
\end{tabular}

\section{Conclusion}

Our review briefly explained the structure and biological role of Jab1. Along with its multifunctional potential, Jab1 regulates numerous cell signaling pathways and associated targets in cancer progression. Jab1 has been proven to be correlated with adverse outcomes and therapeutic responses in cancer patients. Although the exact underlying mechanism remains uncovered, it paves a new direction in the field of anti-cancer treatments. As a potential target of anti-cancer therapies, more Jab1 inhibitory studies are still needed to develop novel therapeutic strategies against numerous carcinomas. Considering the critical involvement of $\mathrm{Jab} 1$ in cancer progression, it is reasonable to consider Jab1as a promising prognostic and diagnostic biomarker for cancer treatment. Furthermore, we have also summarized numerous phytocompounds which could target Jab1 and may emerge as potential anti-cancer drugs. Due to their nontoxic nature, Jab1 inhibition by natural compounds could be a safe and novel approach for chemotherapeutics. However, more preclinical research studies are urgently needed to elucidate more potent combinations with radiotherapy or chemotherapy towards better management of human carcinomas. We strongly believe that this review article would further promote research studies related to the elucidation of specific Jab1 inhibitors in chemoprevention via either one phytocompound or combinatorial approach. Altogether, targeted Jab1 inhibition would emerge as a novel strategy for human cancer prevention in the future. However, more detailed studies are still required to elucidate potent Jab1 specific phyto inhibitors suitable for clinical therapy.

\section{Funding}

This research received no external funding

\section{Acknowledgments}

We thank Noida Institute of Engineering and Technology, Greater Noida, for its immense support.

\section{Conflicts of Interest}

The authors declare no conflicts of interest. 


\section{References}

1. Shackleford, T.J.; Claret, F.X. JAB1/CSN5: a new player in cell cycle control and cancer. Cell Division 2010, 5, https://doi.org/10.1186/1747-1028-5-26.

2. Pan, Y.; Yang, H.; Claret, F.X. Emerging roles of Jab1/CSN5 in DNA damage response, DNA repair, and cancer. Cancer Biology \& Therapy 2014, 15, 256-262, https://doi.org/10.4161/cbt.27823.

3. Wang, L.; Zheng, J.-N.; Pei, D.-S. The emerging roles of Jab1/CSN5 in cancer. Medical Oncology 2016, 33, https://doi.org/10.1007/s12032-016-0805-1.

4. Yoshida, A.; Yoneda-Kato, N.; Panattoni, M.; Pardi, R.; Kato, J.-y. CSN5/Jab1 controls multiple events in the mammalian cell cycle. FEBS Letters 2010, 584, 4545-4552, https://doi.org/10.1016/j.febslet.2010.10.039.

5. Liu, G.; Claret, F.X.; Zhou, F.; Pan, Y. Jab1/COPS5 as a Novel Biomarker for Diagnosis, Prognosis, Therapy Prediction and Therapeutic Tools for Human Cancer. Frontiers in Pharmacology 2018, 9, https://doi.org/10.3389/fphar.2018.00135.

6. Guo, Z.; Wang, Y.; Zhao, Y.; Shu, Y.; Liu, Z.; Zhou, H.; Wang, H.; Zhang, W. The pivotal oncogenic role of Jab1/CSN5 and its therapeutic implications in human cancer. Gene 2019, 687, 219-227, https://doi.org/10.1016/j.gene.2018.11.061.

7. Mokbel, K.; Wazir, U.; Mokbel, K. Chemoprevention of Prostate Cancer by Natural Agents: Evidence from Molecular and Epidemiological Studies. Anticancer Research 2019, 39, 5231-59, https://doi.org/10.21873/anticanres.13720.

8. Gali-Muhtasib, H.; Hmadi, R.; Kareh, M.; Tohme, R.; Darwiche, N. Cell death mechanisms of plant-derived anti-cancer drugs: beyond apoptosis. Apoptosis 2015, 20, 1531-1562, https://doi.org/10.1007/s10495-0151169-2.

9. Ijaz, S.; Akhtar, N.; Khan, M.S.; Hameed, A.; Irfan, M.; Arshad, M.A.; Ali, S.; Asrar, M. Plant derived anticancer agents: A green approach towards skin cancers. Biomedicine \& Pharmacotherapy 2018, 103, 16431651, https://doi.org/10.1016/j.biopha.2018.04.113.

10. Jumpertz, S.; Hennes, T.; Asare, Y.; Schütz, A.K.; Bernhagen, J. CSN5/JAB1 suppresses the WNT inhibitor DKK1 in colorectal cancer cells. Cellular Signalling 2017, 34, 38-46, https://doi.org/10.1016/j.cellsig.2017.02.013.

11. Chamovitz, D.A.; Segal, D. JAB1/CSN5 and the COP9 signalosome. EMBO reports 2001, 2, 96-101, https://doi.org/10.1093/embo-reports/kve028.

12. Schwechheimer, C. The COP9 signalosome (CSN): an evolutionary conserved proteolysis regulator in eukaryotic development. Biochimica et Biophysica Acta (BBA) - Molecular Cell Research 2004, 1695, 4554, https://doi.org/10.1016/j.bbamcr.2004.09.023.

13. Yuan, C.; Wang, D.; Liu, G.; Pan, Y. Jab1/Cops5: a promising target for cancer diagnosis and therapy. International Journal of Clinical Oncology 2021, 26, 1159-1169, https://doi.org/10.1007/s10147-021-019339.

14. Shackleford, T.J.; Zhang, Q.; Tian, L.; Vu, T.T.; Korapati, A.L.; Baumgartner, A.M.; Le, X.-F.; Liao, W.S.; Claret, F.X. Stat3 and CCAAT/enhancer binding protein beta (C/EBP-beta) regulate Jab1/CSN5 expression in mammary carcinoma cells. Breast Cancer Research 2011, 13, 1-6, https://doi.org/10.1186/bcr2902.

15. Pan, Y.; Wang, S.; Su, B.; Zhou, F.; Zhang, R.; Xu, T.; Zhang, R.; Leventaki, V.; Drakos, E.; Liu, W.; Claret, F.X. Stat3 contributes to cancer progression by regulating Jab1/Csn5 expression. Oncogene 2017, 36, 10691079, https://doi.org/10.1038/onc.2016.271.

16. Bramasole, L.; Sinha, A.; Gurevich, S.; Radzinski, M.; Klein, Y.; Panat, N.; Gefen, E.; Rinaldi, T.; JimenezMorales, D.; Johnson, J.; Krogan, N.J.; Reis, N.; Reichmann, D.; Glickman, M.H.; Pick, E. Proteasome lid bridges mitochondrial stress with Cdc53/Cullin1 NEDDylation status. Redox Biology 2019, 20, 533-543, https://doi.org/10.1016/j.redox.2018.11.010.

17. He, W.; Wang, X.; Chen, L.; Guan, X. A Crosstalk Imbalance Between p27Kip1 and Its Interacting Molecules Enhances Breast Carcinogenesis. Cancer Biotherapy and Radiopharmaceuticals 2012, 27, 399-402, https://doi.org/10.1089/cbr.2010.0802.

18. Abdullah, A.; Eyster, K.M.; Bjordahl, T.; Xiao, P.; Zeng, E.; Wang, X. Murine Myocardial Transcriptome Analysis Reveals a Critical Role of COPS8 in the Gene Expression of Cullin-RING Ligase Substrate Receptors and Redox and Vesicle Trafficking Pathways. Frontiers in Physiology 2017, 8, https://doi.org/10.3389/fphys.2017.00594.

19. Wang, S.; Pan, Y.; Zhang, R.; Xu, T.; Wu, W.; Zhang, R.; Wang, C.; Huang, H.; Calin, C.A.; Yang, H.; Claret, F.X. Hsa-miR-24-3p increases nasopharyngeal carcinoma radiosensitivity by targeting both the 3'UTR and 5'UTR of Jab1/CSN5. Oncogene 2016, 35, 6096-6108, https://doi.org/10.1038/onc.2016.147.

20. Nishimoto, A.; Kugimiya, N.; Hosoyama, T.; Enoki, T.; Li, T.-S.; Hamano, K. JAB1 regulates unphosphorylated STAT3 DNA-binding activity through protein-protein interaction in human colon cancer cells. Biochemical and Biophysical Research Communications 2013, 438, 513-518, https://doi.org/10.1016/j.bbrc.2013.07.105. 
21. Yunbao, P.; Francois, X.C. Jab1/Csn5 Signaling in Breast Cancer, Breast Cancer In: Book Breast Cancer From Biology to Medicine. Phuc Van Pham, IntechOpen:United Kingdom, 2017; pp. 200-211, https://doi.org/10.5772/66174.

22. Hsu, M.-C.; Chai, C.-Y.; Hou, M.-F.; Chang, H.-C.; Chen, W.-T.; Hung, W.-C. Jab1 is overexpressed in human breast cancer and is a downstream target for HER-2/neu. Modern Pathology 2008, 21, 609-616, https://doi.org/10.1038/modpathol.2008.23.

23. Nam, A.R.; Kim, J.W.; Park, J.E.; Bang, J.H.; Jin, M.H.; Oh, D.Y.; Bang, Y.J. Jab1 silencing inhibits proliferation and sensitizes to cisplatin in biliary tract cancer. Cancer Res Treat. 2019, 51, 886-900, https://doi.org/10.4143/crt.2018.375.

24. Bapat, P.; Sewell, D.G.; Boylan, M.; Sharma, A.K.; Spallholz, J.E. In Vitro Cytotoxicity of Trastuzumab (Tz) and Se-Trastuzumab (Se-Tz) against the Her/2 Breast Cancer Cell Lines JIMT-1 and BT-474. International Journal of Molecular Sciences 2021, 22, https://doi.org/10.3390/ijms22094655.

25. Hou, J.; Liu, G.; Yuan, Y.; Wang, D.; Jiao, P.; Xing, L.; Pan, Y. Increased Jab1/COPS5 is associated with therapeutic response and adverse outcome in lung cancer and breast cancer patients. Oncotarget. 2017, 8, 97504-15, https://doi.org/10.18632/oncotarget.22146.

26. Hao, Y.; Baker, D.; ten Dijke, P. TGF- $\beta$-Mediated Epithelial-Mesenchymal Transition and Cancer Metastasis. International Journal of Molecular Sciences 2019, 20, https://doi.org/10.3390/ijms20112767.

27. Lai, X.-N.; Li, J.; Tang, L.-B.; Chen, W.-T.; Zhang, L.; Xiong, L.-X. MiRNAs and LncRNAs: Dual Roles in TGF- $\beta$ Signaling-Regulated Metastasis in Lung Cancer. International Journal of Molecular Sciences 2020, 21, https://doi.org/10.3390/ijms21041193.

28. Liu, D.; Song, Z.; Wang, X.; Ouyang, L. Ubiquitin C-Terminal Hydrolase L5 (UCHL5) Accelerates the Growth of Endometrial Cancer via Activating the Wnt/ $\beta$-Catenin Signaling Pathway. Frontiers in Oncology 2020, 10, https://doi.org/10.3389/fonc.2020.00865.

29. Schütz, A.K.; Hennes, T.; Jumpertz, S.; Fuchs, S.; Bernhagen, J. Role of CSN5/JAB1 in Wnt/ $\beta$-catenin activation in colorectal cancer cells. FEBS Letters 2012, 586, 1645-1651, https://doi.org/10.1016/j.febslet.2012.04.037.

30. Chen, Y.; Chen, X.; Yu, J.; Xu, X.; Wei, X.; Gu, X.; Liu, C.; Zhang, D.; Xu, Z. JAB1 is Involved in Neuropathic Pain by Regulating JNK and NF- $\mathrm{KB}$ Activation After Chronic Constriction Injury. Neurochemical Research 2016, 41, 1119-1129, https://doi.org/10.1007/s11064-015-1802-z.

31. Lue, H.; Thiele, M.; Franz, J.; Dahl, E.; Speckgens, S.; Leng, L.; Fingerle-Rowson, G.; Bucala, R.; Lüscher, B.; Bernhagen, J. Macrophage migration inhibitory factor (MIF) promotes cell survival by activation of the Akt pathway and role for CSN5/JAB1 in the control of autocrine MIF activity. Oncogene 2007, 26, 50465059, https://doi.org/10.1038/sj.onc.1210318.

32. Wang, H.; Liu, X.-B.; Chen, J.-H.; Wang, Q.-Q.; Chen, J.-P.; Xu, J.-F.; Sheng, C.-Y.; Ni, Q.-C. Decreased expression and prognostic role of cytoplasmic BRSK1 in human breast carcinoma: Correlation with Jab1 stability and PI3K/Akt pathway. Experimental and Molecular Pathology 2014, 97, 191-201, https://doi.org/10.1016/j.yexmp.2014.07.012.

33. Zhang, Z.; Li, N.; Liu, S.; Jiang, M.; Wan, J.; Zhang, Y.; Wan, L.; Xie, C.; Le, A. Overexpression of IFIT2 inhibits the proliferation of chronic myeloid leukemia cells by regulating the BCR-ABL/AKT/mTOR pathway. Int J Mol Med 2020, 45, 1187-1194, https://doi.org/10.3892/ijmm.2020.4500.

34. Pandey, P.; Bajpai, P.; Siddiqui, H.M.; Sayyed, U.; Tiwari, R.; Shekh, R.; Mishra, K.; Kapoor, V.K. Elucidation of the Chemopreventive Role of Stigmasterol Against Jab1 in Gall Bladder Carcinoma. Endocrine, Metabolic \& Immune Disorders - Drug Targets 2019, 19, 826-837, https://doi.org/10.2174/1871530319666190206124120.

35. Li, J.; Wang, Y.; Yang, C.; Wang, P.; Oelschlager, D.K.; Zheng, Y.; Tian, D.-A.; Grizzle, W.E.; Buchsbaum, D.J.; Wan, M. Polyethylene Glycosylated Curcumin Conjugate Inhibits Pancreatic Cancer Cell Growth through Inactivation of Jab1. Molecular Pharmacology 2009, 76, 81-90, https://doi.org/10.1124/mol.109.054551.

36. Xiao, H.; Claret, F.X.; Shen, Q. The novel Jab1 inhibitor CSN5i-3 suppresses cell proliferation and induces apoptosis in human breast cancer cells. Neoplasma. 2019, 66, 481-6, https://doi.org/10.4149/neo_2018_181016N772.

37. Torres-Cabala, C.; Li-Ning-Tapia, E.; Hwu, W.-J. Pathology-based Biomarkers Useful for Clinical Decisions in Melanoma. Archives of Medical Research 2020, 51, 827-838, https://doi.org/10.1016/j.arcmed.2020.09.008.

38. Lu, Z.; Li, Y.; Che, Y.; Huang, J.; Sun, S.; Mao, S.; Lei, Y.; Li, N.; Sun, N.; He, J. The TGF $\beta$-induced lncRNA TBILA promotes non-small cell lung cancer progression in vitro and in vivo via cis-regulating HGAL and activating S100A7/JAB1 signaling. Cancer Letters 2018, 432, 156-168, https://doi.org/10.1016/j.canlet.2018.06.013.

39. Mamidi, M.K.; Samsa, W.E.; Bashur, L.A.; Chen, Y.; Chan, R.; Lee, B.; Zhou, G. The transcriptional cofactor Jab1/Cops5 is crucial for BMP-mediated mouse chondrocyte differentiation by repressing p53 activity. Journal of Cellular Physiology 2021, 236, 5686-5697, https://doi.org/10.1002/jcp.30254. 
40. Bilsborrow, J.B.; Doherty, E.; Tilstam, P.V.; Bucala, R. Macrophage migration inhibitory factor (MIF) as a therapeutic target for rheumatoid arthritis and systemic lupus erythematosus. Expert Opinion on Therapeutic Targets 2019, 23, 733-744, https://doi.org/10.1080/14728222.2019.1656718.

41. Pandey, P.; Siddiqui, H.M.; Behari, A.; Kapoor, K.V.; Mishra, K.; Sayyed, U.; Tiwari, K.R.; Shekh, R.; Bajpai, P. Jab1-siRNA Induces Cell Growth Inhibition and Cell Cycle Arrest in Gall Bladder Cancer Cells via Targeting Jab1 Signalosome. Anti-Cancer Agents in Medicinal Chemistry 2019, 19, 2019-2033, https://doi.org/10.2174/1871520619666190725122400.

42. Wu, T.; Gu, X.; Cui, H. Emerging Roles of SKP2 in Cancer Drug Resistance. Cells 2021, 10, https://doi.org/10.3390/cells10051147.

43. Pandey, P.; Sayyed, U.; Tiwari, R.K.; Siddiqui, M.H.; Pathak, N.; Bajpai, P. Hesperidin Induces ROSMediated Apoptosis along with Cell Cycle Arrest at G2/M Phase in Human Gall Bladder Carcinoma. Nutrition and Cancer 2019, 71, 676-687, https://doi.org/10.1080/01635581.2018.1508732.

44. Hsu, J.-L.; Chuang, W.-J.; Su, I.-J.; Gui, W.-J.; Chang, Y.-Y.; Lee, Y.-P.; Ai, Y.-L.; Chuang David, T.; Huang, W. Zinc-Dependent Interaction between JAB1 and Pre-S2 Mutant Large Surface Antigen of Hepatitis B Virus and Its Implications for Viral Hepatocarcinogenesis. Journal of Virology 2013, 87, 12675-12684, https://doi.org/10.1128/JVI.01497-13.

45. Schlierf, A.; Altmann, E.; Quancard, J.; Jefferson, A.B.; Assenberg, R.; Renatus, M.; Jones, M.; Hassiepen, U.; Schaefer, M.; Kiffe, M.; Weiss, A.; Wiesmann, C.; Sedrani, R.; Eder, J.; Martoglio, B. Targeted inhibition of the COP9 signalosome for treatment of cancer. Nature Communications 2016, 7, https://doi.org/10.1038/ncomms13166.

46. Wang, Y.; Yu, Y.-n.; Song, S.; Li, T.-j.; Xiang, J.-y.; Zhang, H.; Lu, M.-d.; Ji, F.; Hu, L.-q. JAB1 and phospho-Ser10 p27 expression profile determine human hepatocellular carcinoma prognosis. Journal of Cancer Research and Clinical Oncology 2014, 140, 969-978, https://doi.org/10.1007/s00432-014-1646-y.

47. Pandey, P.; Khan, F.; Maurya, P. Targeting Jab1 using hesperidin (dietary phytocompound) for inducing apoptosis in HeLa cervical cancer cells. Journal of Food Biochemistry 2021, 45, https://doi.org/10.1111/jfbc.13800.

48. Maurya, P.; Pandey, P.; Khan, F.; Mishra, R.; Chaudhary, R.; Singh, S.K. Study to elucidate the inhibitory potential of selected flavonoids against Jab1 in cervical cancer. Biointerface Res. Appl. Chem. 2022, 12, 12901303, https://doi.org/10.33263/BRIAC121.12901303.

49. Kleemann, R.; Hausser, A.; Geiger, G.; Mischke, R.; Burger-Kentischer, A.; Flieger, O.; Johannes, F.-J.; Roger, T.; Calandra, T.; Kapurniotu, A.; Grell, M.; Finkelmeier, D.; Brunner, H.; Bernhagen, J. Intracellular action of the cytokine MIF to modulate AP-1 activity and the cell cycle through Jab1. Nature 2000, 408, 211216, https://doi.org/10.1038/35041591.

50. Wang, J.; Barnes, R.O.; West, N.R.; Olson, M.; Chu, J.E.; Watson, P.H. Jab1 is a target of EGFR signaling in ER $\alpha$-negative breast cancer. Breast Cancer Research 2008, 10, https://doi.org/10.1186/bcr2105.

51. Wei, Y.; Liu, G.; Wu, B.; Yuan, Y.; Pan, Y. Let-7d Inhibits Growth and Metastasis in Breast Cancer by Targeting Jab1/Cops5. Cellular Physiology and Biochemistry 2018, 47, 2126-2135, https://doi.org/10.1159/000491523.

52. Wu, B.; Pan, Y.; Liu, G.; Yang, T.; Jin, Y.; Zhou, F.; Wei, Y. MRPS30-DT Knockdown Inhibits Breast Cancer Progression by Targeting Jab1/Cops5. Frontiers in Oncology 2019, 9, https://doi.org/10.3389/fonc.2019.01170.

53. Chen, H.; Padia, R.; Li, T.; Li, Y.; Li, B.; Jin, L.; Huang, S. Signaling of MK2 sustains robust AP1 activity for triple negative breast cancer tumorigenesis through direct phosphorylation of JAB1. Npj Breast Cancer 2021, 7, https://doi.org/10.1038/s41523-021-00300-1.

54. Choi, H.Y.; Park, N.; Na, J.B.; Ko, E.S.; Park, J.-Y.; Yoo, J.C. Direct binding of Copine3 with Jab1 activates downstream ErbB2 signaling and motility in SKBr3 breast cancer cells. Oncol Rep 2016, 35, 1147-1152, https://doi.org/10.3892/or.2015.4472.

55. Pandey, P.; Khan, F. Jab1 inhibition by methanolic extract of Moringa oleifera leaves in cervical cancer cells: a potent targeted therapeutic approach. Nutr. Cancer. 2020, 29, 1-9, https://doi.org/10.1080/01635581.2020.1826989.

56. Chen, X.; Jia, Y.; Zhang, Y.; Zhou, D.; Sun, H.; Ma, X. $\alpha 5-n A C h R$ contributes to epithelial-mesenchymal transition and metastasis by regulating Jab1/Csn5 signalling in lung cancer. Journal of Cellular and Molecular Medicine 2020, 24, 2497-2506, https://doi.org/10.1111/jcmm.14941.

57. Nishimoto, A.; Takemoto, Y.; Saito, T.; Kurazumi, H.; Tanaka, T.; Harada, E.; Shirasawa, B.; Hamano, K. Nuclear $\beta$-catenin expression is positively regulated by JAB1 in human colorectal cancer cells. Biochemical and Biophysical Research Communications 2020, 533, 548-552, https://doi.org/10.1016/j.bbrc.2020.09.007.

58. Wang, L.; Du, W.-Q.; Xie, M.; Liu, M.-R.; Huo, F.-C.; Yang, J.; Pei, D.-S. Jab1 promotes gastric cancer tumorigenesis via non-ubiquitin proteasomal degradation of p14ARF. Gastric Cancer 2020, 23, 1003-1017, https://doi.org/10.1007/s10120-020-01087-z. 